\title{
The Roman-Irish Bath: Medical/health history as therapeutic assemblage
}

\author{
Ronan Foley \\ Department of Geography, National University of Ireland Maynooth, Maynooth, County Kildare, Ireland
}

\section{A R T I C L E I N F O}

\section{Article history:}

Available online 24 January 2014

\section{Keywords:}

Ireland

Assemblage

Therapeutic landscapes

Turkish Baths

Hydropathy

\begin{abstract}
A B S T R A C T
The invention of a new form of hot-air bath in Blarney, Ireland in 1856, variously known in its lifetime as the Roman-Irish or Turkish Bath, acted as the starting point for a the production of a globalised therapeutic landscape. Tracking the diffusion of the Roman-Irish bath template from its local invention in Ireland to a global reach across the Victorian world and recognizing its place within a wider hydrotherapeutic history, this paper frames that diffusion as a valuable empirical addition to assemblage theory. The specific empirical history of the spread of the Roman-Irish/Turkish bath idea is drawn from primary archival and secondary historical sources. It is then discussed and, drawing from work on assemblage theory, analyzed against three broad themes: mobile networks, socio-material practices and contested emergence. The emergent relational geographies of the Roman-Irish Bath identify important roles for the diffusion and transformation of specific medical settings, identities and functions. These were linked in turn to competing social-healing pathways wherein bodies were technologically and morally managed, to produce a more inhabited form of therapeutic assemblage. In all cases the differential diffusion of the bath idea, it's shifting and fractured material forms and multiple inhabitations and discourses were contested and mobile and spoke to an assemblage approach which has ripe potential for exploration across a range of medical/health geography settings.
\end{abstract}

(c) 2014 Elsevier Ltd. All rights reserved.

\section{Introduction}

On a quiet wooded hillside outside Blarney, Co. Cork, lie the ruins of St. Ann's Hill, once the premier Hydropathic centre in Ireland (Fig. 1). Between 1844 and 1952, the site encapsulated a century of healing history associated with the use of water as a curative element (O'Leary, 2000). The 'Hydro', as it was known locally, sat on the edge of a set of narratives, geographical and medical. It was set in a remote corner of Empire and practiced an unorthodox form of medicine, hydrotherapy (Price, 1981). Yet simultaneously it had worldwide reach, as the starting point for the diffusion of a specific type of medical intervention, an early model of what Hoyez (2007) refers to as a 'globalising therapeutic landscape'. At the 'Hydro', owner Richard Barter invented what became variously known as the 'Roman-Irish', Turkish or Hot-Air Bath, which was to become an important part of the mid-nineteenth century enthusiasm for Hydropathic healing (Neswald, 2010; Price, 1981). Its popularity spread to Britain, Mainland Europe and beyond and glimpses of the original bath model and associated 'sweating-cures' can still be seen in contemporary spa cultures

E-mail address: ronan.foley@nuim.ie.
(Foley, 2010). In tracing that history, this paper uses the material diffusion of the Roman-Irish Bath template (a hybrid form of Turkish Bath with heated rooms and plunge pools) as a means to more fully articulate the theoretical idea of a therapeutic assemblage. Such a term is definable as the application of assemblage thinking to relational aspects of medical/health geography, with a special emphasis on inhabited therapeutic places, practices and networks.

The idea of assemblage has gained prominence in human geography, drawing in part from the writings of Foucault and Deleuze, but also as part of a wider relational geography, in which spatial connections developed through networks and flows lead to a mobile and complex production of place (Cresswell, 2012; Legg, 2011). This paper suggests a valuable intellectual contribution by bringing two research strands, medical/health geography and assemblage theory, closer together. While assemblage ideas are relatively under-explored in medical/health geography, Gesler and Kearns's identification of a braided approach to unite different subdisciplinary traditions echoes Deleuze's metaphor of the dispositif (Deleuze, 1992; Foley, 2011; Gesler \& Kearns, 2002). There are also important theoretical ideas emerging in the area of therapeutic landscapes; on relational experiences (Conradson, 2005; Rose, 2012), contested outcomes (Collins \& Kearns, 2007) and the 


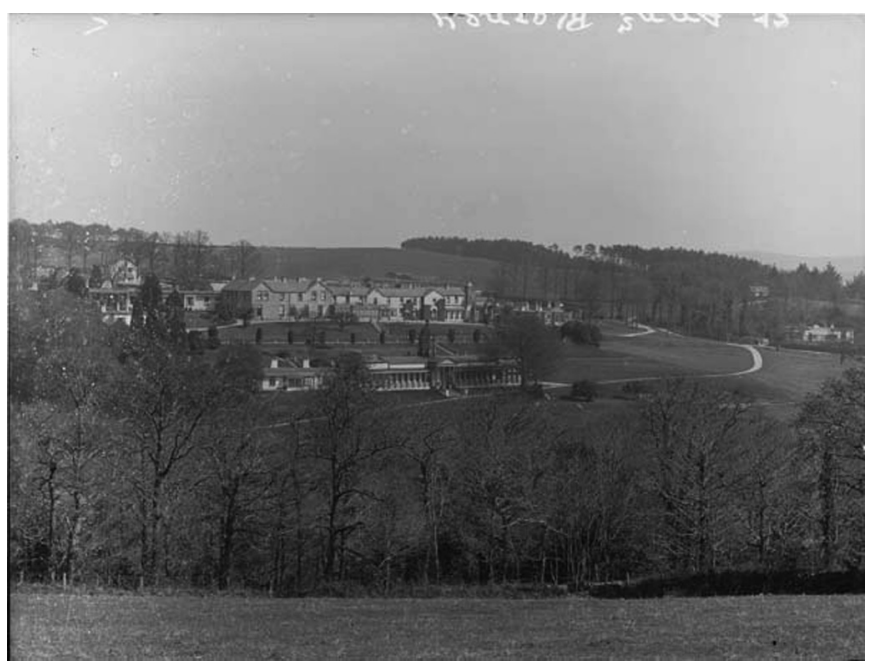

Fig. 1. St. Ann's Hill Hydro with Turkish Baths in foreground. (Source: National Library of Ireland).

production and reproduction of therapeutic spaces (Hoyez, 2007). Such research hints at but does not fully engage with assemblage theory. As a counter-balance, Cresswell (2012) also notes that the excessive complexity of some theoretical writing on assemblage might be improved by better empirical articulation.

The paper will initially discuss a number of theoretical frameworks and potential ways of exploring the assemblage idea in relation to therapeutic landscapes research. A short historical summary will then sketch the development of the Roman-Irish Bath from the 1850s to its lingering traces in the present day. In briefly introducing the context for the development of the initial bath form and the history of its subsequent diffusion, the scene is set for a deeper evaluation of that history as a means to ground assemblage and relational geography thinking. The development of the therapeutic assemblage concept will then be discussed around three core themes, mobile networks, socio-material practices and contested emergence. The paper will finish with a discussion and summary of the potential to develop the idea of a specifically therapeutic assemblage in wider multi-disciplinary ways.

\section{Literature review}

Recent cultural geography research has identified a range of mobile material and immaterial elements - bodies, imaginations, objects, practices, inhabitations - that shape the production of place and form part of a wider set of relational geographies (Cresswell, 2012; Jones, 2009; Wylie, 2007). Within that research, the term assemblage has gained increasing traction. Anderson, Kearnes, McFarlane, and Swanton (2012) suggest the term has been used variously as a descriptor, concept and ethos. As a descriptor assemblage has been used as a definition and as a gathering together of socio-spatial components to form specific geographies. In its use as a concept, they argue it draws from Deleuze and Guattari's (1987) notion of agencement, a process of arranging and fitting together heterogenous constellations of related elements. Finally the term can also be seen as an ethos, embracing methods and materials that are oriented toward instability and novel interactions between elements within that assemblage. The assemblage concept has been applied to a number of geographical subjects including colonial spaces and urban planning and policy (Legg, 2007; McCann, 2011; McGuirk \& Dowling, 2009). At heart is a concern for how diverse materials are combined and recombined in place into different types of temporary stabilization. The above terms help us to understand assemblage as part process, part spatial tension but something that arguably, must have a material form and a set of networked components that change and evolve across time and space (Legg, 2011).

In Anderson and McFarlane's (2011) discussion of the complexity of the assemblage idea, they provide no definitive applications or easy guides to translating the concepts into empirical form. What is valuable is their listing of four inter-related sets of processes. The first of these is that of gathering, coherence and dispersion. Their notion of, '... assembling and re-assembling sociomaterial practices that are diffuse, tangled and contingent' along with a set of spatial and temporal conjunctions that disperse and re-align 'according to place and angle of vision' (p. 125) are intriguing. Secondly, they identify a focus in assemblage on groups, collectives and distributed agencies that incorporate, 'an uneven topography of trajectories that cross or engage each other to different extents over time'. Thirdly, they suggest that assemblage is interested in emergence with a particular interest in power as a set of multiple co-existences and a plurality in transformation. Finally, they note specific concrete aspects of the network as central to the spatial articulation of the assemblage. How to consider these ideas using examples drawn from medical/health geographies is a key starting point for this paper.

Within medical/health geography, the theoretical frameworks that underpin therapeutic landscapes research have become more sophisticated in their 'second wave' (Williams, 2007). The notion of the therapeutic landscape, defined by Kearns and Gesler (1998) as 'places that have achieved lasting reputations for providing physical, mental and spiritual healing (p. 8)', has developed in recent years to consider relational experiences of wellbeing. Examples include how different people experience therapeutic settings in different and at times contested, even anti-therapeutic ways, such as differential retreat experiences and health outcomes at the seaside (Collins \& Kearns, 2007; Conradson, 2005). In addition there has been a developing interest in how therapeutic landscapes are produced and reproduced with examples from festival and religious spaces showing how globalised therapeutic networks, such as spas, wellness retreats and yoga centres, assemble together different tropes, practices and clienteles which are temporarily stabilised but also develop hybrid forms (Hoyez, 2007; Lea, 2006). In all these studies, contested outcomes, multiple identities and agency and the spatial transfer of therapeutic form all suggest the potential of the idea of therapeutic assemblage within empirical studies. One explicit example is the author's work on the holy well, where material sites, symbolic identities associated with patron saints and inhabited dimensions including local curative rituals and narratives all shape the production of a culturally-formed therapeutic landscape (Foley, 2011).

The potential is also evident in linking assemblage ideas to a culturally-focused medical history. Typically, such historical studies, especially as they relate to the subject under discussion here, hydrotherapy, have focused on relationships between orthodox and unorthodox medicine (Neswald, 2010; Price, 1981). Porter (1990), commenting on the medical history of spas, hinted at the importance of assemblage components (as topography and topology) noting that,

Culturally and regionally, the fortunes of water-cures depended heavily upon complex configurations of values, the laws of landownership, and the curves of economic development - to say nothing of the mere accidents of topography and geology. (p. viii)

Finally, Breathnach's (2004) influential paper on the Turkish Bath in Ireland, written from a social history perspective and with 
explicit reference to Barter's Roman-Irish Bath, utilizes a theoretical positionality close to the idea of assemblage, informed by a multi-disciplinary account of how gender, embodiment, class and imagination all shaped the identity of such spaces. Her identification of how the clienteles and practices at the baths shifted between male and female, upper and lower class and ill and healthy bodies all hint at a relational geography shaping the production of such spaces, with both material and immaterial dimensions.

Drawing from the specific processes identified by Anderson and McFarlane (2011) assemblage thinking can, I argue, be traced through the spatial articulation of the Roman-Irish Bath as a specifically therapeutic example. In the first instance, we can describe and explore the mobile networks associated with the bath as an unorthodox medical innovation, as well as its the development and diffusion, a process that was in Anderson and McFarlane's terms, gathered, made coherent and then dispersed. The central role of water, the variant elements of therapeutic design and the fissures and fractures that emerged as the idea the Roman-Irish Bath spread and modified, also emphasised that relational dimension. Secondly, the Roman-Irish Bath can also be considered in terms of a set of socio-material practices, given embodied and cultural meaning through the groups, collectives and distributed agencies associated with the bath. One potential critique of assemblage research is that it remains curiously dis-embodied and needs a deeper articulation of its inhabited components. Aimed at both the wealthy and poorer parts of society and linked to wider Victorian concerns with clean bodies and minds, one can identify a set of medical-moral ideas shaping practices that are simultaneously curative and social. Yet there is also a place in that assemblage for non-human elements, especially technologies, that additionally shape the spaces of the bath/hydro. Finally, Anderson and McFarlane's discussion of the role of contested emergence speaks to a wider dimension of assemblage work, more evident in geo-political examples such as the governance of Colonial Delhi, where the theoretical ordering of space was continually challenged and altered by its messy and conflicting realities (Legg, 2007). From a medical perspective, the relationships between unorthodox (as hydrotherapy was seen) and orthodox medicine and the different and uneven 'topography of trajectories', by which the bath develops beyond Blarney are all aspects of contested narratives within the assemblage. All three themes can be readily identified in the cultural production of the Roman-Irish Bath network, which though marginal and ephemeral at times, had and has a surprising resilience (Foley, 2010). It is, therefore, valuable to initially explore how the history of the Roman-Irish Bath and its articulation as a therapeutic assemblage, can bring about a clearer understanding of the relationship between conceptual and empirical aspects of that term (Robbins \& Marks, 2010).

\section{The Roman-Irish Bath: historical context and cultural diffusion}

\section{Source material}

The primary sources for the paper draw from a range of archival material tracing the history of the Roman-Irish Bath. Malcolm Shifrin's (2013) magisterial website (www.victorianturkishbath. org) is a central resource, being a comprehensive history of the Turkish Bath, its development by Barter in Blarney and subsequent global diffusion and impact, drawing from a wide range of technological, commercial and documentary sources. In addition, local newspaper and written accounts, historic photographs and pamphlets and archival sources such as the Census, historic maps, letters and postcards, all provide valuable primary material (O'Leary,
2000). Given the historical nature and setting of the work, no ethical approval was required.

\section{Hydrotherapy foundations}

In the 1840s, Vincenz Priessnitz developed a new Hydropathic establishment in Gräffenberg in Austrian Silesia (Durie, 2006; Price, 1981). Priessnitz's establishment provided a set of treatments including lengthy cold-water wraps, baths and showers and regular consumption of water, as well as carefully selected diets and regular exercise in the fresh air (Price, 1981). An enthusiastic British visitor, Captain Claridge, brought back the fundamental principles and practices of hydrotherapy as developed by Priessnitz to the British Isles (Price, 1981). The promise of a new form of natural therapy built around the enduring reviving powers of cold water were popular at the time as a new medical treatment, framed by a backlash against then current orthodox medical practices (Porter, 1990). In addition, the cold-water cure had specific associations with clean living, temperance, morality and hygiene, with many of the keenest enthusiasts from religious congregations, such as Quakers and Baptists (Breathnach, 2004; Durie, 2006). Neswald (2010) argued that given the still heterogeneous nature of scientific medicine at the time, hydrotherapy, though treated as unorthodox, was not so outlandish in relative terms. Nonetheless, it did not emerge uncontested and was ridiculed and criticized in some medical quarters (Porter, 1990). In assemblage terms, it was part of a wider blurring and absorption of medical practices, drawn from a range of medical discoveries, folk practices and technological advancement (Foley, 2010).

\section{St. Ann's Hill Hydro, Blarney}

The original farmland site contained a holy well from which the hydro took its name. Richard Barter, a medical doctor, leased the original site in 1842 and as an attendee at one of Claridge's lecture tours, became interested in hydrotherapy (O'Leary, 2000). The craze for hydropathy led to an initial burst of building of Hydropathic establishments, or 'hydros' as they quickly came to be known, from the middle of the 1840s (Durie, 2006; Shifrin, 2013). Barter converted his former farm at St. Ann's Hill into a hydro, initially with a small number of beds offering treatments to patient visitors. In the early years it was explicitly advertised as 'The Irish Gräffenberg' in a conscious homage to Priessnitz (O’Leary, 2000).

During the 1850s Barter experimented with designing a new form of non-steamy Turkish Bath at St. Ann's Hill. His design, whose primary innovation was the removal of steam into vents within the side walls, became the template for a global explosion of Turkish Bath building in the following decades (Shifrin, 2013). In form, Barter's Roman-Irish Baths consisted of a set of rooms of increasing heat; refridarium (warm), tepidarium (hot at around $100{ }^{\circ} \mathrm{F}$ ) and sudatorium (very hot at up to $150{ }^{\circ} \mathrm{F}$ ). In addition, a number of plunge baths to cool the body were part of a medicalised process of perspiration and detoxification (Neswald, 2010). His hydro, subsequently run by his son and grand-nephew, maintained its popularity and clientele of wealthy Anglo-Irish and occasional foreign visitors as it developed new hydropathic treatments through the late 19th and early 20th centuries. There was an interruption when the Barter's gave over the hydro to act as an auxiliary hospital during the World War I and it then resumed business after 1918. With Irish independence, the traditional clientele drifted away and its commercial viability was challenged throughout the 1930s and 1940s and after several unsuccessful changes of ownership it finally closed its doors in 1953. Despite an attempt by Barter's greatgrandson to revive the Hydro in 1967, all that is left are some 
ruins, though relatives of the last owner still farm there (Colthurst Papers, 1967).

\section{Diffusion: globalising the Roman-Irish Bath}

From the start, the exportation and development of the form from its Blarney base was characterized by slippery identities and conflicting cultural metaphors. Though he developed the idea as much from historic Roman thermae as from hammams, Barter himself initially used the term 'improved Turkish Bath' and chose a hot dry air method as a specifically therapeutic design given, 'the pure atmosphere of the bath, which retains sufficient natural moisture for all healthful purposes' (Barter, 1858). His first baths beyond Blarney were built for medico-moral purposes for the poor in Cork City as well as in nearby asylums (Shifrin, 2013). In turn, he set up a company to develop commercial Turkish Baths in locations like Dublin, Limerick and even London. Light, marble and interior design elements such as stained glass and fountains were significant components of the therapeutic template that also characterised early reproductions such as the Lincoln Place Baths in Dublin in 1860 (Fig. 2). Barter kept a firm hand and financial interest in early baths built to his template, but he died in 1870 . Quite quickly, there were departures from the original template as new entrepreneurs in Dublin and elsewhere expanded on the design, introducing steam and additional cosmetic services to the baths (Shifrin, 2013).



Fig. 2. Lincoln place Turkish Baths. (Source: Irish historical picture company).
The template also spread across the British Isles with well over 100 baths built in the later decades of the 19th century (Fig. 3). Durie noted the first Scottish examples using the Barterian template in Edinburgh and Aberdeen as early as 1859 as well as the template's survival, in both physical and moral forms, in Scottish hydros at Dunblane and Craiglockhart (Durie, 2006). One of the most significant 'diffusion events' was a visit by developers from Baden-Baden in the 1870s to Richard Barter's son, also called Richard, to observe and get permission to bring the template to Germany, where they were explicitly named as 'Irisch-Römisches Bad' at Baden-Baden and Wiesbaden.

As the idea spread, both conceptually and in its built and operational aspects, there were two lines of development. At the original site in Blarney, Barter's son and grand-nephew ran St. Ann's Hill Hydro from 1870 until the 1920s as a more explicitly hydrotherapeutic institution, in which a series of resident physicians and increasingly technological treatments were mixed with a health 'resort and retreat' identity. While there was a social dimension to this strand, this was much more explicit in the urban expansion of the bath template, wherein luxurious and cosmetic identities became much more prominent (Breathnach, 2004). There was also a parallel shift in agency with the St. Ann's Hill Hydro sustaining its relatively upper-class and Anglo-Irish clienteles, whereas the urban Turkish Baths, set in more competitive commercial settings, were moved to open their doors to a much broader class base. In these settings, the volatile commercial success of the baths meant regular changes of management, location and form as the assemblage shifted to accommodate changing fashions and demands (Shifrin, 2013).

\section{Lingering traces}

The specific operation of the original Turkish Bath at St. Ann's Hill Hydro came to an end during World War I, in part because of the lack of coal. Globally, the craze for Turkish Baths faded early in the twentieth century though not before the construction of baths, loosely based on the Barterian template, in locations as diverse as San Francisco and Dunedin (Shifrin, 2013). Yet in a range of different ways, within which health, gender, luxury and even sexuality played a role, the therapeutic form of the Turkish bath has sustained and even been re-invented within contemporary spa cultures, in locations like Edinburgh, Harrogate and Wiesbaden (Foley, 2010). In addition, its ongoing expression as a 'sweat-cure' location forms a relational and connective narrative through to more everyday global settings like hammams, banias and saunas, wherein the interweaving of healing and social meanings remain significant. The lingering trace of the Roman-Irish Bath in German spas forms part of that narrative (Fig. 4), yet it sits within a wider global industry of spa networks, increasingly franchised and corporate. In the tracing of that narrative through its Mediterranean and Germanic origins, its Hibernian re-invention and subsequent reexportation back to that German-speaking world, one sees an assemblage idea that stretches across time and space, yet also represents a complex cultural formation.

\section{The Roman-Irish Bath as therapeutic assemblage}

\section{Mobile networks}

In considering the Roman-Irish Bath as a representative therapeutic assemblage, both its starting point and its diffusion across a complex relational geography, were explicitly associated with water. Water acted as the literal source, with the idea of the RomanIrish Bath flowing from the site along a series of networks, linked by medical enthusiasm, innovation, entrepreneurship and evolving 

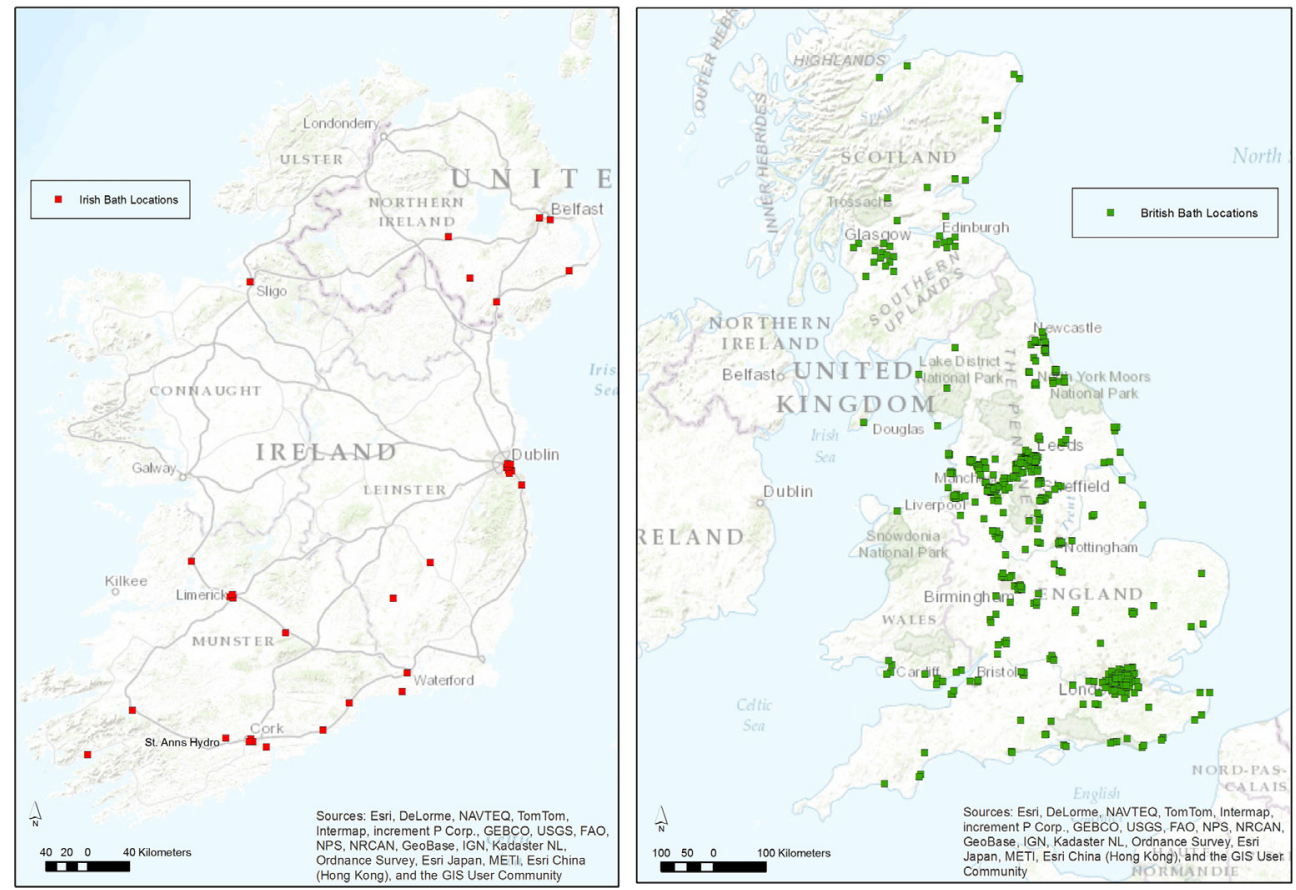

Fig. 3. Locations of Baths in Ireland and Britain.

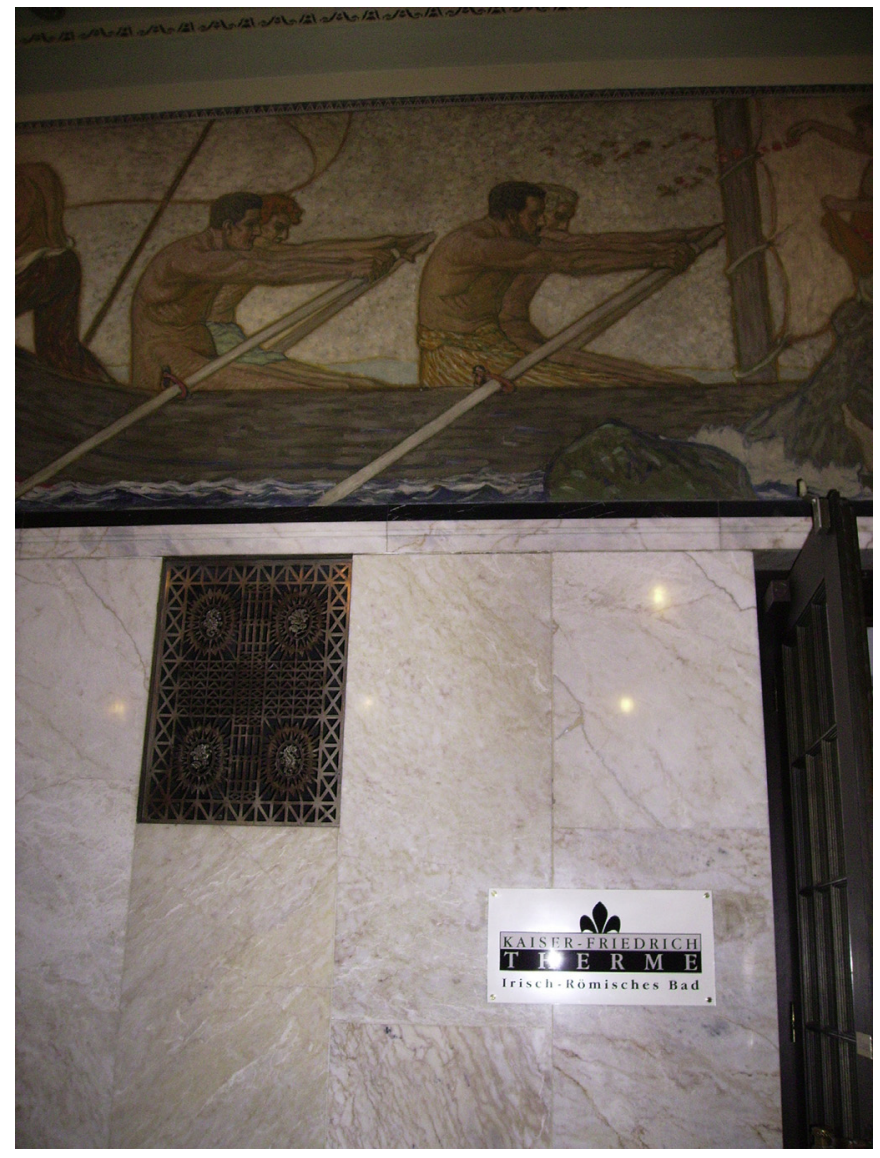

Fig. 4. Entrance to the Kaiser-Friedrich Therme, Wiesbaden. (Source: Author). built and technological forms. The original site was named after a holy well dedicated to St. Ann, located to the north of the site and this association with healing water was a well-established cultural trope (Foley, 2010). The whole site was literally built around water and a local supply scheme brought essential supplies from the Shouragh River for the operation of the hydro. Water also acted as a food source via the on-site fish farm (O'Leary, 2000). On a more fundamental basis, the raison d'etre of a Hydropathic establishment was the ability of water to cure, not just through bathing, but also through additional water-based treatments. Water was central to both the medical practices at the site and its wider curative appeal. Hydrotherapy was founded on cold-water wraps, baths and showers, but morphed over time to warmer water-based treatments like the Turkish Bath and ultimately to the electric baths of the later 19th century (Durie, 2006). Water also formed part of the wider therapeutic settings in the grounds and parks of hydros, where walks in the woods and by streams were built as much for visitors and accompanying guests as the patients. In St. Ann's and more famously, in Craiglockhart's underground swimming pool, water had additional value in wartime hydros as recuperative and restorative ingredients for deeply wounded soldiers (Barker, 1996; Webb, 2006).

In assemblage terms then, water acted as a catalyst for the gathering, coherence and dispersion of a therapeutic idea, which flowed out across the network but was always connected and related to the original form. Barter's first baths beyond Blarney were specifically owned by him and he was centrally involved in their design and management. In time, as the Roman-Irish Bath spread to Britain and Germany and other managers and owners became involved, the form of the baths changed, with the arrival of steam in particular, making them more sauna-like in operation (Shifrin, 2013). There were other fractures within that process, evident in the ways in which urban baths departed from the Barterian template via alterations shaped by location and the commercial intent of the developers (Anderson \& McFarlane, 2011). This was especially evident in the less medico-moral and more publicsocial versions of the baths at St. Stephen's Green or Lincoln Place 
in Dublin (Breathnach, 2004). At the latter, new owners in 1867 announced an intent to specifically introduce steam which ran counter to Barter's template and within four years were also running a high-class French Restaurant there (Shifrin, 2013).

The mobile network of the Roman-Irish Bath and its overlaps with Turkish bath reproductions also reflected connective dimensions of assemblage. This operated in two different forms: one material, the other more symbolic, even immaterial. The rise of interest in the specific forms and practices of hydrotherapy underpinned the production of a globalised therapeutic assemblage (Hoyez, 2007; Williams, 2007). The deliberate transposition of a medical practice involved not just Barter's particular bath form, but more widely the cold water treatments, the cold sheet bath, the sitz bath or the freezing douche, to become part of a global hydro template (Durie, 2006; Foley, 2010). Hoyez's (2007) exploration of the globalised therapeutic landscape identified how a foundational yogic site in Rishikesh, India, had its symbolic elements - river, mountain, temple, spiritual power - reproduced in new sites in Scotland and the US. While more implicit in her work, both examples identify an assemblage, using a mix of authentic and hybrid material forms and immaterial symbolic components, as characteristic of globalised therapeutic settings.

As a second component, the more symbolic elements of the Roman-Irish Bath provided a certain exoticism (almost Orientalist), wherein a network of imaginative associations ran across the related forms of bath, hydro and spa (Breathnach, 2004). These were evident in the dramatic exterior chimneys and minarets, which provided an exoticised public face to the baths, a characteristic also of other Bath settings in the UK and beyond (Breathnach, 2004). An immaterial exotic association existed as a layering on top of the material form to suggest a complex connection between the social spaces in which they were developed and how the image and physical presence of the Roman-Irish Baths, was at all times a temporary settling of multiple identities and difference (Anderson et al., 2012).

\section{Socio-material practices}

Many different subjects and objects can be mapped onto the sites associated with the Roman-Irish Bath: patients, medics, masseuses, technicians, wounded soldiers, passing visitors, managers, families, cooks, porters and domestic servants. Any healing site contains within it an assemblage of bodies who, depending on one's positionality, are the subjects or objects of a set of medical/health treatments with quite different performances by class and health status. Bodies act as markers of both class and health outcomes but also as nodes or actants within a wider relational geography (Cresswell, 2012). The movements of Barter, the mixed clienteles of the baths and the other entrepreneurs and developers, all attest to that relationality, which always had an embodied component (Shifrin, 2013).

The typical patient at St. Ann's came from the Anglo-Irish community with a mix of genders and ages, though there were also wealthier Catholic visitors. Census data from 1911 recorded 78 guests and visitors (and 28 staff), the youngest aged two, the oldest, 96 years old. As markers of class, the recorded occupations identified professional groups ranging from barristers and retired military to a "Master Manufacturer of Underclothing" recorded in the 1901 Census (NAI, 2013). The performances at the Hydro, pictured in images from the turn of the 19th century, show a typically Victorian cast of elderly matrons, children and staff engaged in relaxation, rest and therapies such as "fresh-air baths" (O'Leary, 2000). A postcard from the Hydro (Fig. 5) provides a rare glimpse of a patient voice with therapeutic intent, writing home to Waterford: "Have come down here for a change and I hope it will help to bring back my strength, WJD."

Within hydrotherapeutic sites more generally, a braided narrative, following different strands of social narrative and embodied form, within a broadly agreed direction of intent, focused on the relationships between cleansing water and cleaned bodies. Anderson and McFarlane (2011) highlight group/collective agency as important assemblage components and one can identify the role of the 'hydro body' and a managed body in place as part of that ethos. A strong moral geography underpinned the initial development of the Roman-Irish Bath at St. Ann's that was extensively reworked and reproduced elsewhere. Graffenberg House in Barnet, England, operated from a very similar, almost evangelical positionality based on an assumed relationship between good health and good morals. This was explicitly connected in its promotional texts to then current legislation on hygiene and public health (Metcalfe, 1877). St. Ann's also became a site of retreat for Father Matthew, a famous Irish temperance campaigner, while Barter's first external baths evoked a paternalistic concern for the poor of Cork, within a sub-text of weaning them off strong drink and immorality, a feature also of Scottish Hydros (Durie, 2006). In 1860 he opened the Working Class Turkish Baths in Belfast, followed in

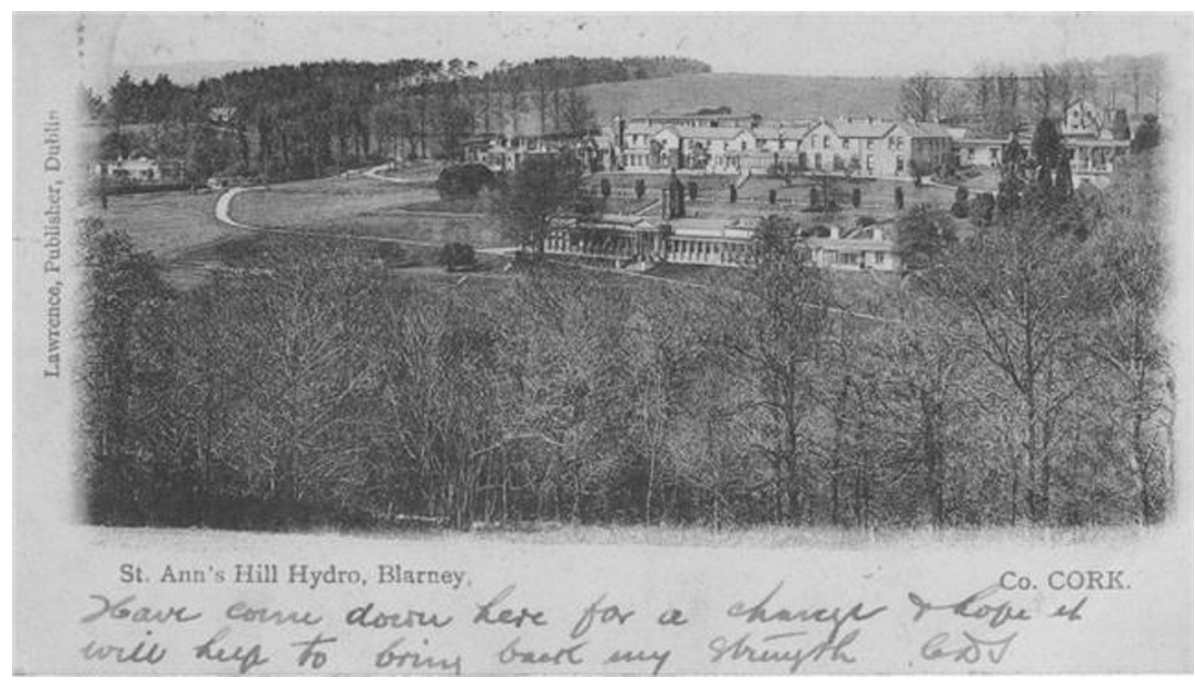

Fig. 5. Postcard from St. Ann's Hydro, c1910 (Source: Tim O'Brien). 


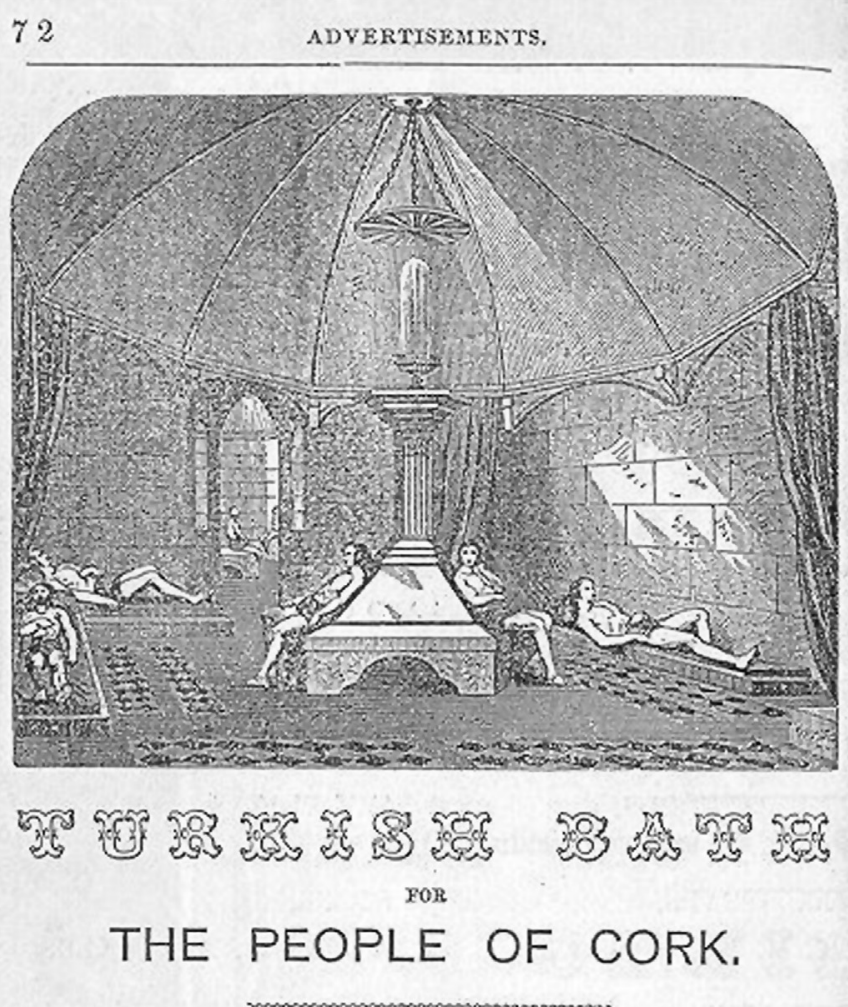

The IMPROVED TURKISH or ROMAN BATHS, for the POOR, are now in course of erection in

\section{MAYLOR STREET, CORK.}

Funds for the purpose having been obtained by roluntary contributions, and by a large grant in aid from the Trustees of "The Barter Bath Charity Fund."

Henry \& Coghlan, Printers, Georgo's-st.

Fig. 6. Advert for Maylor Street Baths, Cork (Source: Shifrin, 2013).

1863 by the Turkish Baths for the Destitute Poor in Cork's Maylor Street (Fig. 6). This construction followed earlier experimentation on Barter's own estate of which he noted:

I have erected a complete bath for the poor at my own expense, and they resort to it in hundreds; and see what a boon this is...! It removes ... the necessity for stimulant drinks; and ... is the means best calculated to take from Ireland its two great evils intemperance and filth

Shifrin, 2013.

At the Roman-Irish Bath and hydro there was a continuum of healthy to ill bodies, whose relationships shifted and changed as they were healed or returned for further treatment and whether they were just passing by or merely tourists. During the war, one of the roles of St. Ann's (as well as Craiglockhart and other hydros) was as an auxiliary hospital aimed to make the convalescent patient well enough to go back into battle (O'Leary, 2000). Here the patient (and indeed place) role was temporary, but acted as a node on a wider embodied network, with 'cured' soldiers sent back to the Front as part of wider circulatory role for the war body. The war body at St. Ann's, and at more famous examples from Dunblane and Craiglockhart, consisted of patients with amputated limbs and neurasthenia - the war-time code for shell-shock - for whom illhealth was more lasting (Barker, 1996; Durie, 2006). There is the suggestion that the medical staff at St. Ann's gained additional expertise in early forms of physiotherapy as part of the convalescent treatment for shell-shocked and physically wounded soldiers. The Hydro, in a lingering trace of knowledge gained within the assemblage, promoted its new expertise in 'post-traumatic joint troubles', in the years immediately after the war (O'Leary, 2000).

\section{Contested emergence}

Yet the development and exportation of the Roman-Irish Bath idea was, as many assemblages were, non-linear and prone to 'fragility and provisionality, gaps, fissures and fractures linked to the process of gathering and dispersion' (Anderson \& McFarlane, 2011, p. 125). As DeLanda (2011) notes, it is also possible for the components that form an assemblage to simultaneously work on stabilizing identity, forcing change and enabling transformation. Apart from the period of World War 1, the St Ann's Hydro was always a commercial venture, but the development within it of a new form of Turkish Bath and its commodification as a healing template was an emergent assemblage process that was identifiably transformed and contested medically, commercially and structurally.

Medically, as was the case with hydrotherapy more generally, the commercial spread of the Roman-Irish Bath model led to a set of contested debates between orthodox and complementary medics, in which Barter Senior became embroiled. Complaints were made as to the dangers of excess heat and steam in Turkish Baths, especially those with heart conditions, but Barter was swift to refute such claims and noted that if there were steam in any of the baths, they were certainly not his (Durie, 2006). The immediate departure of some of the Dublin baths to a 'steamier format' was of course a departure from the careful medical planning of Barter and in subsequent decades there were additional court cases over medical negligence such as at the Stephens Green baths, where 'improper supervision' led to a further challenge to the medical credibility of hydrotherapy more broadly (Shifrin, 2013). The St Ann's Hydro noted in its brochures in the 1920s the use of a range of douches, “...hot, cold, rapid control, steam and the 'Aix-Vichy' douche massage," along with a range of medical baths. An electrotherapeutic department was developed for the treatment of "neuro-muscular and arthritic diseases by the electric current, and ionisation" with reference also made to a "Bergonic Faradic apparatus" for the treatment of obesity (O'Leary, 2000, p. 26). Harry Barter at the time referred to this assemblage of treatments as "ergotherapy" and this exotic naming of treatments was both a strength and weakness of the hydrotherapeutic movement, as it was lampooned as pseudo-science in both medical and imaginative texts (Price, 1981). Such debates were linked to fears of new treatments and technologies, where burdens of proof and efficacy and attempts to maintain existing allopathic power structures linger into contemporary discussions around complementary and alternative medicine (Doel \& Segrott, 2003).

In developing the Roman-Irish Bath as a commercial idea, Barter initially worked closely with early baths built beyond Blarney, in Bray and Dublin, operating them as a shareholder and investor and effectively franchising out those first examples (Durie, 2006; Shifrin, 2013). Yet many of the baths were commercial failures with baths at Bray and Ennis lasting less than ten years (Davies, 2007). As a response to the difficulties of making the baths solvent, one began to see fissures and fractures in how they were designed and operated. These fractured aspects of assemblage were evident in a tension between therapeutic and entrepreneurial input - in 
assemblage terms stability and transformation - and how one needed to depart from the original model just to sustain the idea. As new baths, opened their doors to poorer patrons in Dublin and beyond, they began to co-locate other businesses, such as restaurants and hairdressers, and any sense of control associated with the idea of franchise rapidly disappeared (Foley, 2010). In most cases, it was more of a franchise of emergent ideas, a hotch-potch, typical of many assemblages, where original strict designs on form, process, usage and clientele, blurred and merged together. The non-linear nature of that emergence was especially evident in the standalone urban baths, whereas St. Ann's and other Hydropathic establishments were able to better withstand the commercial pressures due to wider assemblages of treatments and facilities they operated within (Foley, 2010; Shifrin, 2013).

In a parallel aspect of the therapeutic assemblage, the diffusion of the Roman-Irish Bath saw a distinct structural shift in its meaning and function. From an originally deep focus on health and well-being, the later versions rapidly assumed less healthy and more social, even decadent, sets of identities (Breathnach, 2004; Shifrin, 2013). As well as the buildings themselves, the inhabitations and performances were also an important dimension of the assemblage, with mobile spaces being shaped by mobile behaviours. Baths and hydros were not simply empty spaces and technologies, they were enacted on by social bodies, who had the means to transgress established practices, and for whom the use of the baths, especially urban ones, to do business, take their leisure or even engage in furtive sexual practices (a feature noted in Joyce's Ulysses) were all part of a fluid production of place evident in the contested identity of the baths as a social as much as a healing place (Breathnach, 2004; Mackaman, 1998).

\section{Discussion}

Anderson et al. (2012) start their consideration of assemblage by identifying it as a process that involves the aforementioned components of descriptor, ethos and concept. This paper seeks to clarify the definition of the term in setting it within a therapeutic milieu and from that study of the Roman-Irish Bath, extends the idea through the introduction of more embodied and inhabited components. One can identify from this history, a process of assembling and re-assembling of both ethos and concept starting from a place which was constantly relational to its surroundings, its cultural contexts, socio-spatial patterns and wider discussions around medical orthodoxy. Yet in assemblage terms what was also apparent from the empirical work was the ways in which fissures and fractures were evident in social and medical power, in commercial entrepreneurship, and in the multiple fidelities to, and strayings from, its original physical and inhabited templates. Durie (2006) noted the shifts from purely medical/health identities of the first wave of hydros to the later more socialized sites, where overlapping spa identities were especially evident. In Anderson and McFarlane's terms, one can also read the Roman-Irish Bath as an object example of an assemblage of durable orders, repeating earlier Classical forms and flexible enough to bear modification and hybridisation. The design of a set of rooms of increasing heat with their associated hydrotherapeutic treatments are evident still in the indigenous settings of the sauna and hammam, yet also shape new associated aspects of the assemblage such as spas and bath-houses in the contemporary world.

In its own promotional brochures, the Hydro stated;

'He (Barter) first re-introduced into Western Europe the treatment of disease by hot air and hot water in the form of what is now known as the Turkish Bath, the famous Roman bath of classical times. It is described on the Continent as the Roman-
Irish Bath, by which name its use by the Romans and revival in Ireland by Dr. Barter are combined and commemorated'

Anon, 1869.

These contradictory narratives reflect the discursive and material hybridization associated with many globalised therapeutic landscapes (Hoyez, 2007). In the same way, the multiple Roman, Islamic, Ottoman, German and Irish descriptors of the Roman-Irish Bath show the extent in which an assemblage was inscribed and at times dis-assembled. That confusion of terminology was almost deliberate with multiple cultural identities tied into the assemblage, which in turn were overlaid by multiple forms of practice (evolving hydrotherapies and medical treatments) and additional social, luxurious, even liminal representations of the baths (Breathnach, 2004). In their discussion of descriptors Anderson and McFarlane (2011) note substantial difficulties with pinning down concrete definitions and terminology, yet one can track through the Roman-Irish Bath how it incorporates those elements of assemblage that form a "constellation of difference" in its diffusion over time and space. I would argue in fact that such theoretical notions must contain some concrete fixity of source to make sense of its non-concrete possibilities, but also note that the diffusion of the Roman-Irish Bath was always an active process, a globalising as well as globalised therapeutic landscape.

The assemblage of the Roman-Irish Bath can therefore be seen as a relational entity: a container (of sweating cures, therapeutic design and medico-moral practice) but also a distributor (through economic expansion and reproduction) within which Barter was a central node. He acted as both a conduit and disseminator of received knowledge, which led to experimentation and entrepreneurship. That entrepreneurship was reflected in the template of the bath, which was taken on by others and given a new set of cultural, social and environmental meanings. In time, those changes, the admission of steam, of barbers, of the lower classes, saw a change and decline, tracked in part by changes in wider societal technologies which brought warm water into most people's houses and made public bathing less necessary (Porter, 1990). Yet there was a different path for the more hydrotherapeutic aspects of the business, in which a new hybrid ethos of the hydro/spa became a strong but lingering trace across a range of medical and health cultures. Bodies remained part of this diffusion and they too were diffuse, from the wealthy manufacturer at Blarney to the poor Corkonian at the Maylor Street baths and down the generations of the Barter family. In a range of cultural practices reassembled anew across time and space, a mix of healthy and unhealthy bodies were encountered, treated in an unorthodox even alternative medical setting which was always contested yet somehow appreciated for its imaginative therapeutic power, a concept that sustains in the contemporary spa retreat (Foley, 2010).

\section{Summary}

\section{Porter (1990) noted that the history of spas}

'...demonstrate(d) the degree to which past cultures of health were complex performances - enterprises shared between the sick and the medical profession ... within a matrix of resources, institutions, amenities and physical buildings; and drawing upon elaborate rituals of regimen ... they satisfied a deep desire that the healing enterprise should proceed within frameworks essentially sociable in their nature, and suffused with symbolic cultural meanings'

Porter, 1990, p. xii. 
Porter's prescient quote channels a strong sense of assemblage thinking, flagging up of a complexity of performance, a shared enterprise, a matrix of actants and a set of social and cultural frameworks, all of which are equally evident in the history of the Roman-Irish Bath. In its complex emplacement within a wider hydrotherapeutic history, there is value in framing that narrative against the notion of a therapeutic assemblage. Missing from both is a more explicit concern for the performative/inhabited dimensions of assemblage, which have been relatively absent in theoretical discussions up to now. The role of inhabitation and how human behaviours shape therapeutic landscapes more generally speaks to those processual, malleable and mutable elements of assemblage, and indeed part of the reason behind how an assemblage is developed/produced. The Roman-Irish Bath is but one example of a culturally shaped health practice, with embodied and built components and 'elaborate rituals of regimen' (Porter, 1990, p. xii). These were expressed within 'matrixed' material geographical spaces and places in which people performed health and where health was performed on people.

A key aspect in debates on the effectiveness of the Roman-Irish Bath and for hydrotherapy more broadly was the notion of the body managed back to health. This applied to both the proponents and opponents of the Barter model, within which proper supervision and regulation were central themes. One can even glimpse a tension with overtones of contested power - between the role of the medical supervisor and the non-adherent patient, whose bodily mis-orders can ultimately be managed, even overpowered, by a set of moral and technological solutions. Yet as Porter (1990) notes, the healing enterprise also had social and symbolic cultural meaning and the reputational identity of the bath, in its different spatial articulations was central to what success the Roman-Irish version had.

In drawing on the theoretical writing of Anderson and MacFarlane, interactions, stability and transformation are important in their discussion of descriptor, concept and ethos. They themselves note a struggle in how assemblage may be both an object of study or a constructed method. When drawing from the therapeutic landscapes field, assemblage thinking arguably contains elements of both and can provide a valuable theoretical foundation, especially in historical work. It has been applied in a public health policy arena but less fully in historical cultural studies research (McCann, 2011). In considering the health history of a particular medical form I would like to think the idea of a therapeutic assemblage may add to methodological learning by making scholars think through and map out the different relationships between medical spaces, patient bodies and the contested social diffusion of a theoretical idea. It can be seen as a braided approach (a term also noted by Deleuze in his discussion of the idea of dispositif) wherein multiple channels exist, overlap, merge and occasionally stop, but all ultimately move forwards in time and space (Deleuze, 1992; Gesler \& Kearns, 2002). This approach, utilising a range of overlapping materials and approaches, may also become part of what assemblage theory brings to medical/ health history. Such an approach would also pay attention to a topological account of the networks of subjects and objects that are deeper components of that assemblage. One might also suggest that more expansive theoretical connections between assemblage, actornetwork theory and even non-representational theory are ripe for development, especially in relation to technologies and patient practices (Anderson et al., 2012; Wylie, 2007). In developing other narratives, there are interesting but under-developed lines of enquiry based on patient/visitor accounts, where the experience and immersion in the therapeutic environment can enlighten us on how assemblage is lived and operationalised.

In using the case-study of the Roman-Irish Bath, I am also drawing on the potential for deepening theoretical work in similar therapeutic settings world-wide. The reputation of the hydro and a curative outcome were co-dependent (though less than one might think) and tied in to the production of bodies healed or made well. To apply the idea of a therapeutic assemblage, there generally has to be some sort of specific focus or origin point for that assemblage and again a site-based approach works well in this regard. Yet it also opens up the prospect of disassembling and reassembling, especially when that relates to relational and marginal spaces and processes. For St. Ann's and the Barter family, the developmental place of the bath/hydro was marked by points of rupture (e.g. world and local wars, financial difficulties) and points of distillation (i.e. its reinvention of the Turkish bath and its position as part of a globalised network). The ways in which medical fashions shifted and changed over time, shifts that were sometimes whimsical, sometimes structural, also clarified the relational geography of this and other sites. They also marked it with a loss of place, and though it lingers now in material ruins, it remains in local memory. Perhaps one of the functions of historic therapeutic assemblage research is to somehow concretise those memories and the attendant relational geographies that made them, while they still breathe life.

\section{References}

Anderson, B., Kearnes, M., McFarlane, C., \& Swanton, D. (2012). On assemblages and geography. Dialogues in Human Geography, 2(2), 171-189.

Anderson, B., \& McFarlane, C. (2011). Assemblage and geography. Area, 43(2), 124 127.

Anon. (1869). A glimpse of St. Ann's, the hydropathic establishment of Dr. Barter near Cork. Penzance: Beare and Son.

Barker, P. (1996). Regeneration. London: Viking.

Barter, R. (1858). The rise and progress of the Irish Graffenberg. Public Lecture, July 8 th, 1858.

Breathnach, T. (2004). For health and pleasure: the Turkish Bath in Victorian Ireland. Victorian Literature and Culture, 32(1), 159-175.

Collins, D., \& Kearns, R. (2007). Ambiguous landscapes: sun, risk and recreation on New Zealand beaches. In A. Williams (Ed.), Therapeutic landscapes (pp. 15-32). Aldershot: Ashgate.

Colthurst Papers. (1967). Letters from R.W. Barter U196A/1372. Cork: Cork City Archives.

Conradson, D. (2005). Landscape, care and the relational self: therapeutic encounters in rural England. Health E Place, 11, 337-348.

Cresswell, T. (2012). Geographical thought: A critical introduction. London: WileyBlackwell.

Davies, M. (2007). That favourite resort. The story of Bray, Co. Wicklow. Bray: Wordwell.

DeLanda, M. (2011). Philosophy and simulation: The emergence of synthetic reason. New York: Continuum.

Deleuze, G. (1992). What is a dispositif? In T. J. Armstrong (Ed.), Foucault: Philosopher (pp. 159-168) New York: Harvester Wheatsheaf.

Deleuze, G., \& Guattari, F. (1987). A thousand plateaus: Capitalism and schizophrenia. Minneapolis: University of Minnesota Press.

Doel, M., \& Segrott, J. (2003). Beyond belief? Consumer culture, complementary medicine, and the dis-ease of everyday life. Environment and Planning D, 21 $739-759$.

Durie, A. (2006). Water is best: The hydros and health tourism in Scotland 1840-1940. Edinburgh: John Donald.

Foley, R. (2010). Healing waters: Therapeutic landscapes in historic and contemporary Ireland. Farnham: Ashgate.

Foley, R. (2011). Performing health in place: the holy well as a therapeutic assemblage. Health \& Place, 17(2), 470-479.

Gesler, W., \& Kearns, R. (2002). Culture, place and health. London: Routledge.

Hoyez, A.-C. (2007). From Rishikesh to Yogaville: the globalization of therapeutic landscapes. In A. Williams (Ed.), Therapeutic landscapes (pp. 49-64). Aldershot: Ashgate.

Jones, M. (2009). Phase Space: geography, relational thinking, and beyond. Progress in Human Geography, 33(4), 487-506.

Kearns, R., \& Gesler, W. (1998). Putting health into place. Syracuse: Syracuse University Press.

Lea, J. (2006). Experiencing festival bodies: connecting massage and wellness. Tourism Recreation Research, 31(1), 57-66.

Legg, S. (2007). Spaces of colonialism: Delhi's urban governmentalities. Oxford: Blackwell.

Legg, S. (2011). Assemblage/apparatus: using Deleuze and Foucault. Area, 43(2), $128-133$.

Mackaman, D. (1998). Leisure settings: Bourgeois culture, medicine and the spa in Modern France. Chicago: University of Chicago Press.

McCann, E. (2011). Veritable inventions: cities, policies and assemblage. Area, 43(2), 143-147. 
McGuirk, P., \& Dowling, R. (2009). Neoliberal privatization? Remapping the public and the private in Sydney's masterplanned residential estates. Political Geography, 28, 174-185.

Metcalfe, R. (1877). Sanitas Sanitatum et Omnia Sanitas. London: Co-Operative Printing Company.

National Archives of Ireland (NAI). (2013). Census of Ireland 1901/1911. Retrieved 8th March, 2012, from www.census.nationalarchives.ie.

Neswald, E. (2010). Asserting medical identities in mid-nineteenth century Ireland: the case of the water cure in Cork. In J. Adelman, \& E. Agnew (Eds.), Science and technology in nineteenth-century Ireland (pp. 32-46). Dublin: Four Courts Press.

O'Leary, S. (2000). St. Ann's Hydro, Old Blarney. Journal of the Blarney and District Historical Society, 5, 3-31.

Porter, R. (1990). The medical history of waters and spas: introduction. In R. Porter (Ed.), Medical history, supplement no. 10 (pp. vii-xii). London: Wellcome Institute.
Price, R. (1981). Hydropathy in England, 1840-1870. Medical History, 25, 269-280. Robbins, P. \& Marks, B. (2010). Assemblage Geographies. In S. Smith, R. Pain, S. Marston, \& J. P. Jones, III (Eds.), The Sage handbook of social geographies (pp. 176-194). London: Sage.

Rose, E. (2012). Encountering place: a psychoanalytic approach for understanding how therapeutic landscapes benefit health and wellbeing. Health $\mathcal{E}$ Place, 18 , 1381-1387.

Shifrin, M. (2013). Victorian Turkish baths: Their origin, development, Er gradual decline. Retrieved 12th February, 2013, from http://www.victorianturkishbath.org/.

Webb, T. (2006). 'Dottyville' - Craiglockhart war hospital and shell-shock treatment in the first world war. Journal of the Royal Society of Medicine, 99, 342-346. Williams, A. (Ed.). (2007). Therapeutic landscapes. Farnham: Ashgate.

Wylie, J. (2007). Landscape. Abingdon: Routledge. 